\title{
The Complex Function Method Roadway Section Design of the Soft Coal Seam
}

\author{
Shihao Tu, ${ }^{1,2}$ Zhaoxin Li, $^{1,2}$ Zhiwei Ye, ${ }^{1,2}$ Cun Zhang, ${ }^{1,2}$ and Lei Zhang ${ }^{1,2}$ \\ ${ }^{1}$ School of Mines, China University of Mining and Technology, Xuzhou City, Jiangsu 221116, China \\ ${ }^{2}$ Key Laboratory of Deep Coal Resource Mining, Ministry of Education of China, Xuzhou 221116, China \\ Correspondence should be addressed to Cun Zhang; cumt_zc@163.com and Lei Zhang; lz811@uowmail.edu.au
}

Received 30 January 2016; Revised 24 August 2016; Accepted 7 September 2016

Academic Editor: Ibrahim Zeid

Copyright (c) 2016 Shihao Tu et al. This is an open access article distributed under the Creative Commons Attribution License, which permits unrestricted use, distribution, and reproduction in any medium, provided the original work is properly cited.

As for the sophisticated advanced support technique of vertical wall semicircle arch roadway in the three-soft coal seam, a design of flat top U-shape roadway section was put forward. Based on the complex function method, the surrounding rock displacement and stress distribution laws both of vertical wall semicircle arch roadway and of flat top U-shape roadway were obtained. The results showed that the displacement distribution laws in the edge of roadway surrounding rock were similar between the two different roadways and the area of plasticity proportion of flat top U-shape roadway approximately equals that of vertical wall semicircle arch roadway. Based on finite element method, the bearing behaviors of the U-type steel support under the interaction of surrounding rock in vertical wall semicircle arch roadway and flat top U-shape roadway were analyzed. The results showed that, from a mechanics perspective, U-type steel support can fulfill the requirement of surrounding rock supporting in flat top U-shape roadway and vertical wall semicircle arch roadway. The field measurement of mining roadway surrounding rock displacement in Zouzhuang coal mine working face 3204 verified the accuracy of theoretical analysis and numerical simulation.

\section{Introduction}

Roadway section design should mainly consider the following factors: the lithology of surrounding rock, geometric characteristic of roadway section, and support technology.

The lithology of surrounding rock should be considered firstly when designing roadway section. The surrounding rock stability of roadways with the same section will be different if the lithology of surrounding rock is different. Nowadays, many coal mines have entered the phase of deep mining. The difference of the mechanics property between deep rock mass and the rock mass of shallow stratum and the rheology of soft rock under high stress result in the control problem of soft rock stability in many coal mines. The average excavation of soft rock roadway is around $1800 \mathrm{~km}$ per year in China with a ratio of $30 \%$ among all roadways excavated and the repairing rate of soft rock roadway is about $70 \%$ [14], which is extremely high. In summary, the design of soft rock roadway section should be considered thoroughly and a proper design will reduce the difficulties of surrounding rock control.
The stability of roadway surrounding rock has a close relationship with the roadway section [5]. Even under the same geological conditions, the differences of surrounding rock stability between different roadway sections are distinguishable. In order to select a proper section to keep the stability of roadway surrounding rock, displacement field and stress field of roadway surrounding rock should be analyzed. Present literatures usually abstract the roadway and tunnel into harmonic hole in semi-infinite space or infinite space making use of conformal mapping and then calculate stress and displacement around the roadway. Using complex function method, Muskhelishvili [6] elaborated the fundamental theory about the analysis of stress and displacement around the hole. Besides, he also summarized many research works before the 1950s and systematically researched the stress and displacement distribution characteristics around the hole in the elastic body under different boundary conditions [7]. Bjorkman and Richards $[8,9]$ have investigated the stress field and the first invariant of stress tensor around the harmonic hole under uniform load and nonuniformly distributed load. With the usage of boundary element method, 


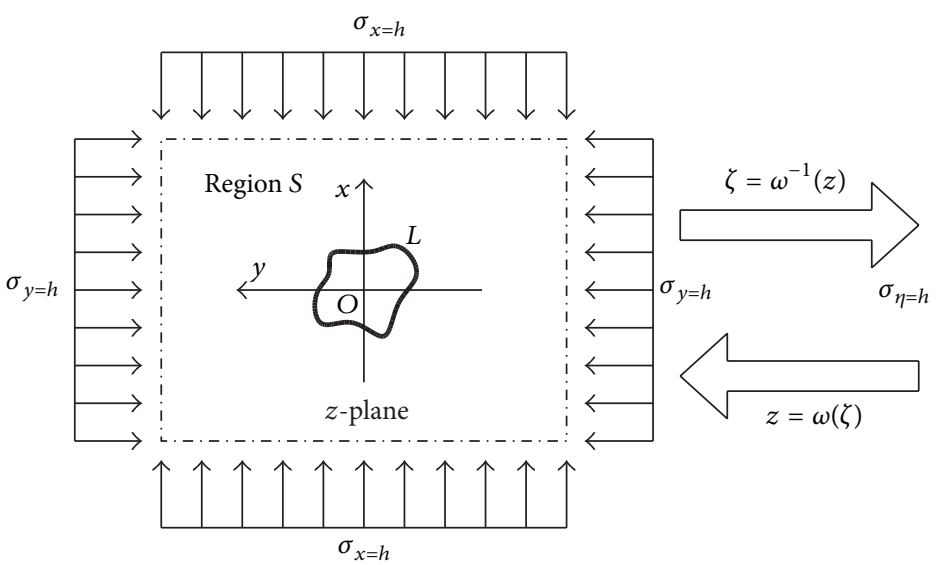

(a)

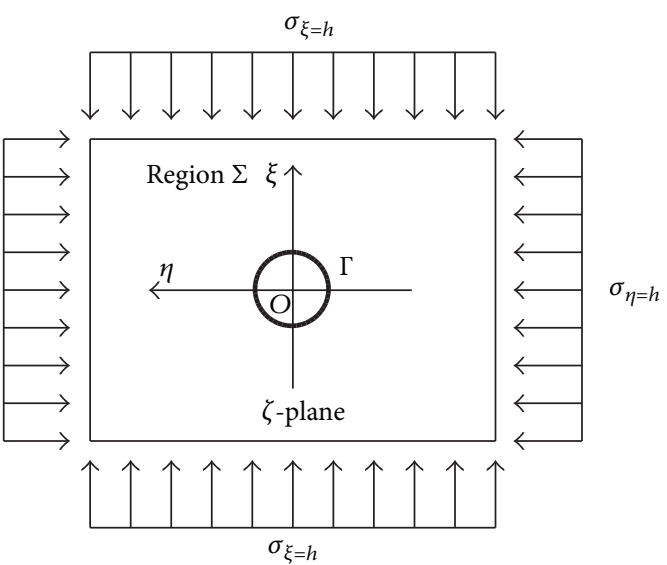

(b)

FIGURE 1: Schematic diagram of load on roadway surrounding rock.

Brady and Bray [10] carried out a research about the stress and displacement distribution law around a hole with an arbitrary shape under the arbitrary triaxial stress condition. Cristescu and Paraschiv [11] researched the surrounding rock stress and displacement distribution law of rectangular-like caverns with different aspect ratio, considering the rock as an isotropic elastic object, and checked how much one has to round off the corners of the cross section in order to obtain an optimal solution. Three particular cases are examined in some detail: wide rectangular-like caverns, square-like caverns, and tall rectangular-like caverns. Several possible ratios of the far-field stresses and several possible internal applied pressures are considered. Dhir [12] developed an analytical/numerical procedure which yields the optimum geometry for a constrained hole shape in a large plate under prescribed boundary stresses at infinity and demonstrated this procedure by the optimization of a square-like (doublebarrel shape) hole with rounded corners. Dawson and Munson [13] calculated the creep deformation characteristics of surrounding rock in a deep potassium salt mine by numerical method. Kienzler and Zhuping [14] deduced a set of more simple equations under the polar coordinates. These equations were used to calculate the hoop stress distribution of a hole's edge in an infinite plane under the arbitrary plane load.

For the supporting of the soft rock roadway, U-type steel support has more advantages than any other supporting method [15]. U-type steel support is widely used in the roadway supporting system [16-18]. The bearing capacity of U-type steel support can be very high with proper usage. When confronted with high load of surrounding rock, Utype steel support can be coused with other supporting techniques. U-type steel support has a wide range of adaption and can be used in the different surrounding rock condition. With the shrinking property, U-type steel support can adapt to the huge deformation of surrounding rock and avoid being damaged severely. Besides, the installation progress of U-type steel support is less complex and the cost is relatively low.
The numerical method is usually adopted to research the U-type steel support in present literatures. Based on orthogonal experiment theory, with the help of theoretical analysis and finite element method software ANSYS, Gao and Li $[19,20]$ calculated and compared the bearing capacities of U-type steel support in horseshoe roadway, circular roadway, and semicircle arch roadway under different load. Xie et al. [21] calculated the maximum bearing capacity of U-type steel support in vertical wall semicircle arch roadway under different combination of loads. Using BEAM189 structural unit in ANSYS, Liu [22] researched the distribution of bending moment, shear force, and axis force of U-type steel support. Using FLAC, Wang et al. [23] researched the load distribution of $U$-type steel support in vertical wall semicircle arch roadway and three-centered roadway with the legs of U-type steel support fixed and unfixed. The result showed that, in deep roadway, the measure of fixing legs with anchor can increase the stability of U-type steel support. Xue [24] theoretically analyzed the whole stability and bearing capacity of the U-type steel support and discussed the mechanics mechanism under different loads by finite element method software ABAQUS. The result showed that, with the help of reinforcement structure, the bearing capacity of $U$-type steel support increased a lot.

In summary, a properly designed roadway section which comprehensively considered the lithology of surrounding rock, geometric characteristic of roadway section, and support technology is meaningful to the safe and high efficiency production of working face in three-soft coal seam.

\section{Analytical Solution of Roadway Surrounding Rock Displacement}

2.1. Establishment of Mechanics Model. The mechanics model of roadway surrounding rock can be described as an infinite elastic plane with a hole, as shown in Figure 1. The stress boundary conditions are as follows: $h$ is the depth of 


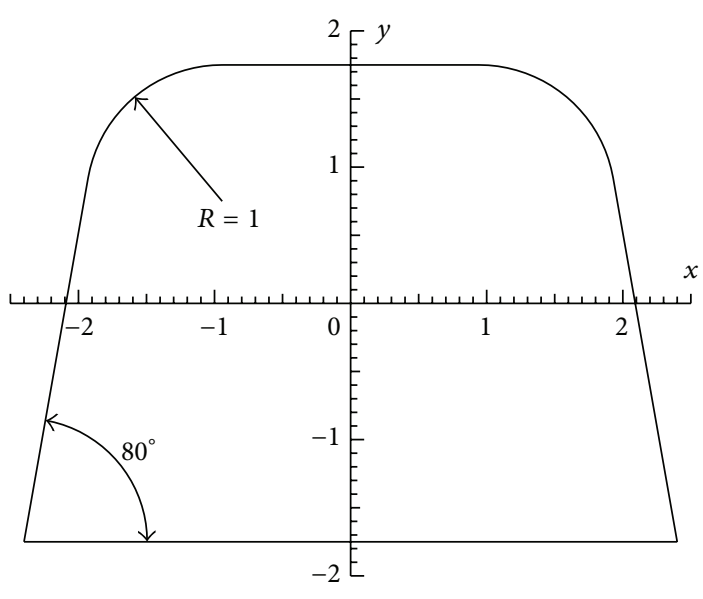

(a) Flat top U-shape section

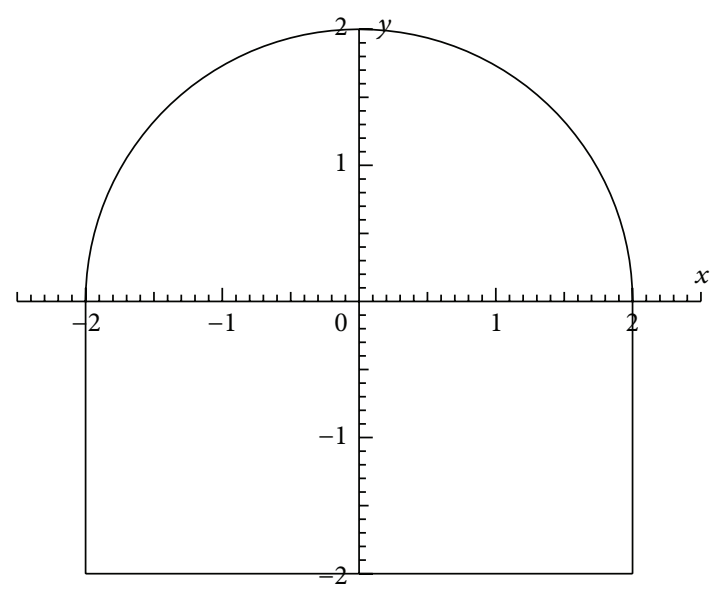

(b) Vertical wall semicircle arch section

FIGURE 2: Geometric parameters of two kinds of roadway section.

the roadway; the vertical stress of the upper boundary and lower boundary is $P=\sigma_{x=h} ; \beta$ is the angle between $P$ and $x$ axis; the horizontal stress of the left boundary and the right boundary is $Q=\sigma_{y=h}$; one should notice that $\sigma_{y=h}=\lambda \sigma_{x=h}$, while $\lambda$ is side pressure coefficient.

As shown in Figure 1(b), roadway section is in the complex plane, $z ; L$ is the roadway section boundary; the surrounding rock of roadway is the area outside $L$, that is, region $S$. Through conformal mapping $z=\omega(\zeta)$, region $S$ was mapped to the area outside the unit circle $\Gamma$ in the complex plane $\zeta$, that is, region $\Sigma$.

As for the infinite simply connected domain like region $S$ and region $\Sigma$, the Laurent expansion of mapping function $z=\omega(\zeta)$ in the region $\Sigma$ existed. In the practice calculation process, there is no need to calculate infinite terms of $a_{k} \zeta^{-k}$. The summation of the first $m$ terms is enough to meet the requirement of computational accuracy, which yields

$$
z=\omega(\zeta)=r\left(\zeta+\sum_{k=0}^{m} a_{k} \zeta^{-k}\right)
$$

while $r \in R ; a_{k} \in C ; m \in N$.

2.2. Solution of the Mechanics Model. The rectangular, trapezium, and arch shapes are widely adopted in the coal mine when it comes to the design of the section of mining roadway $[25,26]$. Considering the difficulty of the roadway support in three-soft coal seam, a design of flat top U-shape section was put forward. The geometric parameters of flat top U-shape roadway section and vertical wall semicircle arch roadway are given in Figure 2.

According to the solving method put forward by Lv and Zhang [5], the mapping functions of flat top U-shape roadway and vertical wall semicircle arch roadway are as follows, respectively:

(1) Mapping function of flat top U-shape roadway

$$
\begin{aligned}
z & =\omega(\zeta)=\frac{222}{100}\left(\zeta-\frac{1}{10}-\frac{11}{100 \zeta}+\frac{15}{100 \zeta^{2}}-\frac{11}{100 \zeta^{3}}\right. \\
& \left.-\frac{3}{100 \zeta^{4}}+\frac{2}{100 \zeta^{5}}-\frac{12}{1000 \zeta^{6}}-\frac{5}{1000 \zeta^{7}}\right) .
\end{aligned}
$$

(2) Mapping function of vertical wall semicircle arch roadway

$$
\begin{aligned}
z= & \omega(\zeta)=\frac{222}{100}\left(\zeta-\frac{1}{10}-\frac{11}{100 \zeta}+\frac{15}{100 \zeta^{2}}-\frac{11}{100 \zeta^{3}}\right. \\
& \left.-\frac{3}{100 \zeta^{4}}+\frac{2}{100 \zeta^{5}}-\frac{12}{1000 \zeta^{6}}-\frac{5}{1000 \zeta^{7}}\right) .
\end{aligned}
$$

According to (2) and (3), the curves of mapping functions are shown in Figure 3.

Considering that the body force of rock mass, that is, gravity, is a constant, one can convert the plane strain problem to the solving of a bioharmonic equation under fixed boundary conditions with respect to a stress function denoted by $U[7]$ :

$$
\frac{\partial^{4} U}{\partial x^{4}}+2 \frac{\partial^{4} U}{\partial x^{2} \partial y^{2}}+\frac{\partial^{4} U}{\partial y^{4}}=0
$$

Goursat put forward the general solution of (4) in 1898 $[7,18]$ :

$$
U=\operatorname{Re}\left[\theta_{1}(z)+\bar{z} \varphi_{1}(z)\right]
$$




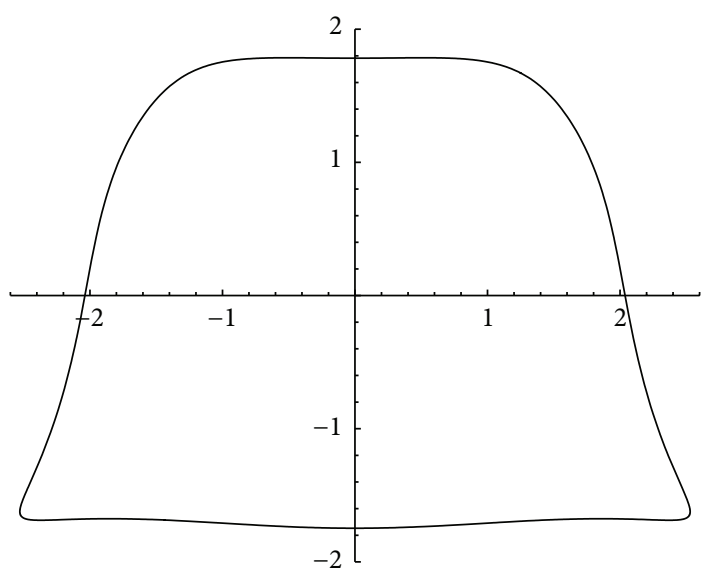

(a) Flat top U-shape section

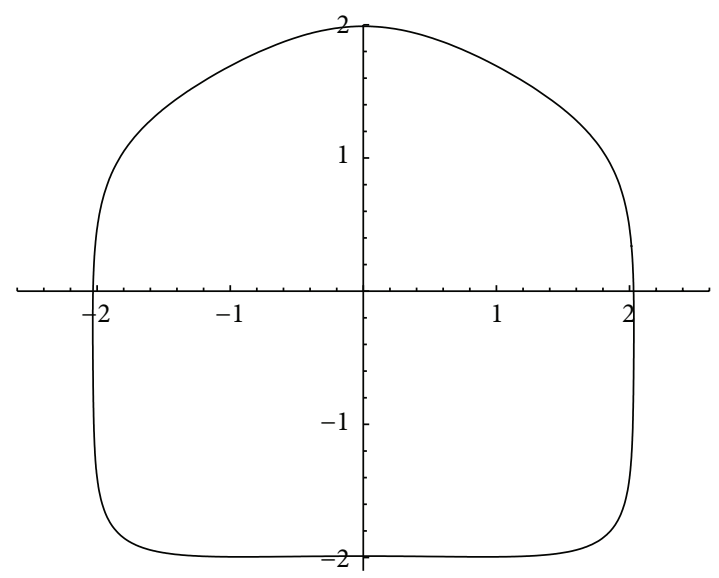

(b) Vertical wall semicircle arch section

FIGURE 3: Mapping result of mapping function.

Combining the solving methods put forward, respectively, by Lv and Zhang [5] and Lu [7], the analytical expressions of displacement component and stress component were obtained:

$$
\begin{aligned}
u & =\frac{1}{E} \operatorname{Re}\{1 \\
& \left.+\nu\left[(3-4 \nu) \varphi(\zeta)-\frac{\omega(\zeta)}{\overline{\omega^{\prime}(\zeta)}} \overline{\varphi^{\prime}(\zeta)}-\overline{\psi(\zeta)}\right]\right\}, \\
v & =\frac{1}{E} \operatorname{Im}\{1 \\
& \left.+\nu\left[(3-4 \nu) \varphi(\zeta)-\frac{\omega(\zeta)}{\overline{\omega^{\prime}(\zeta)}} \overline{\varphi^{\prime}(\zeta)}-\overline{\psi(\zeta)}\right]\right\}, \\
\sigma_{x} & =2 \operatorname{Re}[\Phi(\zeta)] \\
& -\operatorname{Re}\left\{\frac{1}{\omega^{\prime}(\zeta)}\left[\overline{\omega(\zeta)} \Phi^{\prime}(\zeta)+\omega^{\prime}(\zeta) \Psi(\zeta)\right]\right\}, \\
\sigma_{y} & =2 \operatorname{Re}[\Phi(\zeta)] \\
& +\operatorname{Re}\left\{\frac{1}{\omega^{\prime}(\zeta)}\left[\overline{\omega(\zeta)} \Phi^{\prime}(\zeta)+\omega^{\prime}(\zeta) \Psi(\zeta)\right]\right\}, \\
\tau_{x y} & =\operatorname{Im}\left\{\frac{1}{\omega^{\prime}(\zeta)}\left[\overline{\omega(\zeta)} \Phi^{\prime}(\zeta)+\omega^{\prime}(\zeta) \Psi(\zeta)\right]\right\} .
\end{aligned}
$$

In (7), $\Phi(\zeta)=\varphi^{\prime}(\zeta) / \omega^{\prime}(\zeta)$ and $\Psi(\zeta)=\psi^{\prime}(\zeta) / \omega^{\prime}(\zeta)$. Both $\psi(\zeta)$ and $\varphi(\zeta)$ are solvable single-value analytic functions. Because the explicit expressions of displacement component and stress component are very complex, they are not given here. According to the geological condition of Zouzhuang coal mine, the mechanics parameters of roadway surrounding rock are as follows: vertical stress $P=15 \mathrm{MPa}$, side pressure coefficient $\lambda=1.0$, Poisson ratio $v=0.33$, elastic modulus $E=2.1 \mathrm{GPa}$, cohesion $C=2.3 \mathrm{MPa}$, and internal friction angle $\varphi=44^{\circ}[27,28]$. By substituting the mechanics parameters into (6) and (7), both displacement component and stress component of an arbitrary point in surrounding rock can be calculated.

The most obvious result of roadway surrounding rock displacement is the deformation of roadway section, which is described by the displacement of roadway edge. With the origin of the rectangular coordinate given in Figure 2 as the pole and the positive semiaxis of $y$-axis as the polar axis, the polar coordinate is established. For every point of the boundary of roadway section, we can calculate the displacement of the point and the corresponding polar angle (denoted by PA). The curves of the displacements of roadway edge, that is, the boundary values of (6), are given in Figure 4.

According to (6), the curves of the following functions are drawn: the boundary values of displacement with respect to polar angle and the difference of the same displacement component of the two boundaries (i.e., flat top U-shape roadway and vertical wall semicircle arch roadway) with respect to polar angle. For the convenience of description, the terminologies flat top U-shape roadway and vertical wall semicircle arch roadway are denoted by FUS and ARC, respectively, in Figure 4. As it can be seen from Figure 4, the roadway edge displacement distributions of flat top U-shape roadway and vertical wall semicircle arch roadway are similar both in magnitude and in curve shape, which is quite different from the intuition that the difference of surrounding rock displacement between flat top U-shape roadway and vertical wall semicircle arch roadway is distinguishable.

According to (7), the stress tensor of an arbitrary point in surrounding rock can be obtained. Using Mohr-Coulomb criterion, the plasticity proportion of surrounding rock can be determined, as shown in Figure 5. Taking Figure 5(a) as an example, the black area shows the section of flat top U-shape roadway and the gray area denotes the plasticity proportion, while the white area means the elastic part of surrounding rock. It can be seen that the geometric character of the upper part of plasticity proportion in Figure 5(a) is similar to that in Figure 5(b), and only the geometric characters of the bottom part in flat top $U$-shape roadway and vertical wall semicircle 


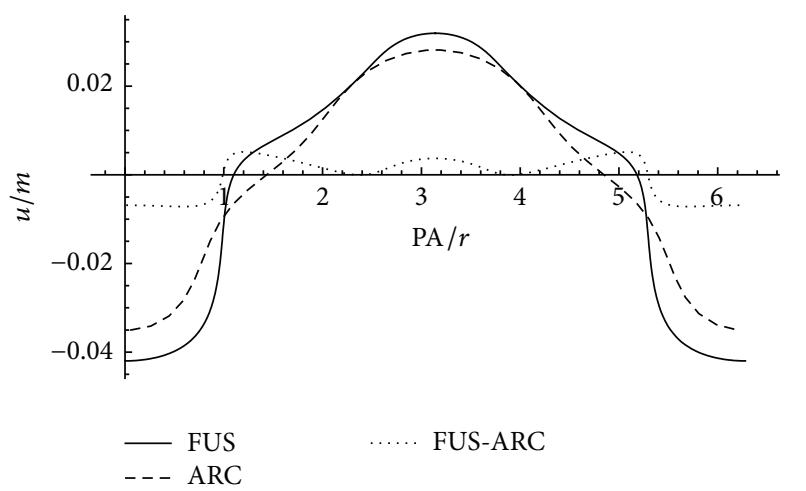

(a) Displacement component $u$

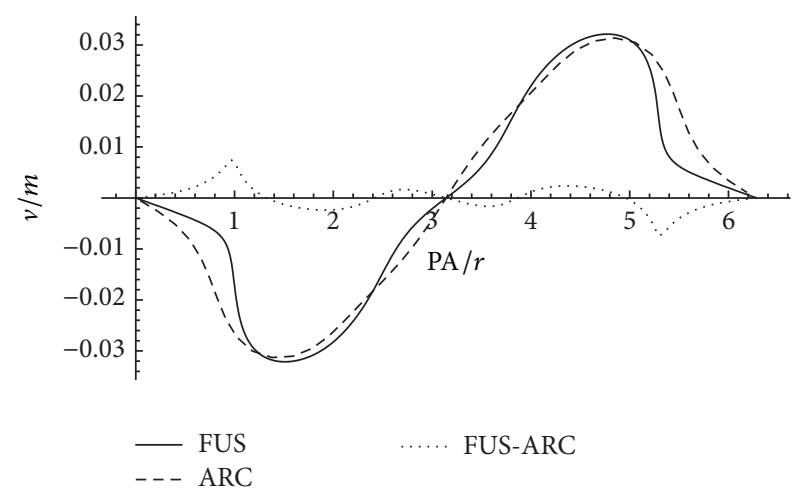

(b) Displacement component $v$

FIgURE 4: The analysis of displacement components.

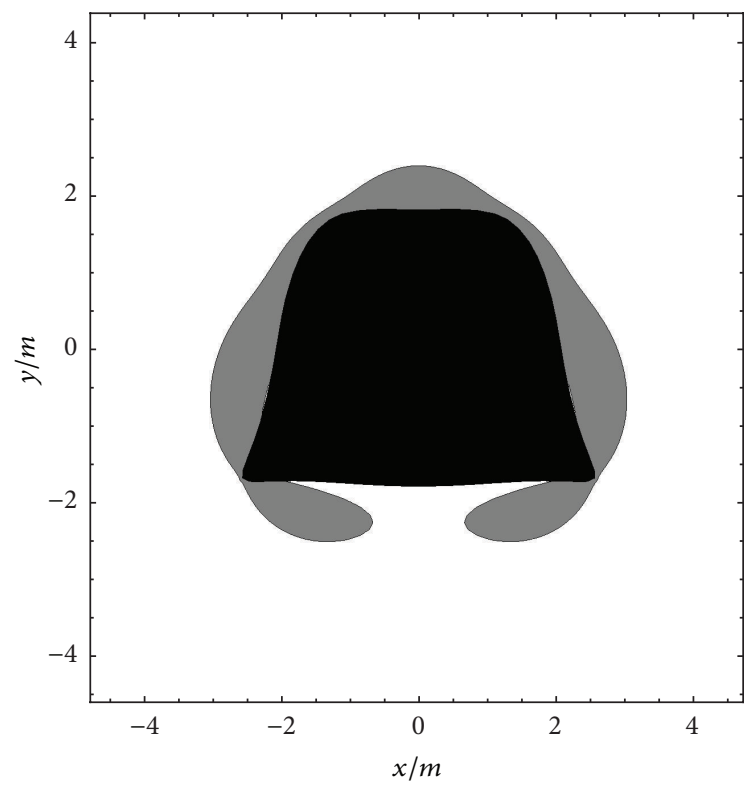

(a) Flat top U-shape roadway

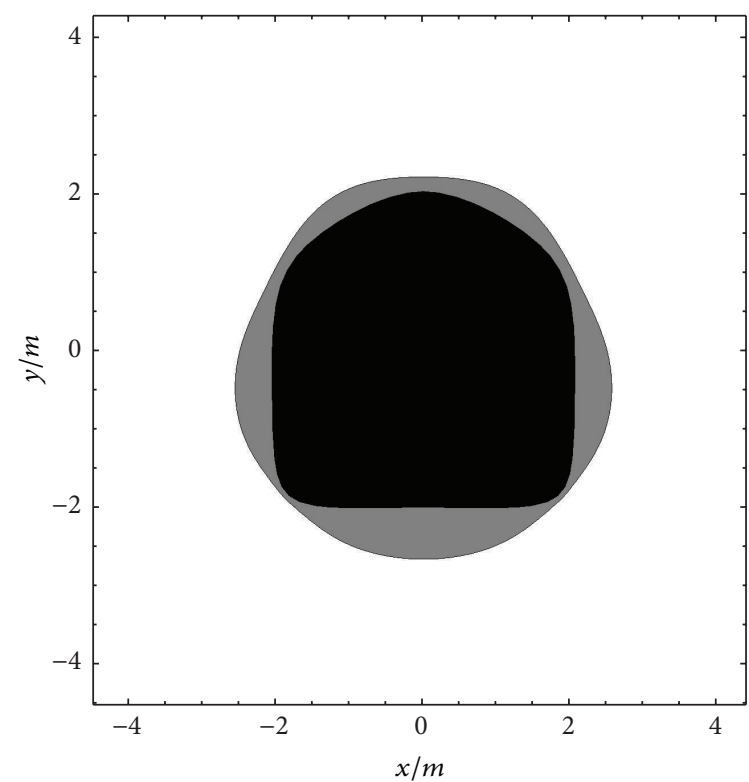

(b) Vertical wall semicircle arch roadway

FIGURE 5: Plasticity proportion of surrounding rock.

arch roadway are different from each other. Despite the difference, the area of plasticity proportion in Figure 5(a) resembles that in Figure 5(b) with a ratio of 1.10 to 1.

With the displacement and stress analysis above and from an engineering perspective, flat top U-shape roadway is a competitive alternative when it is complicated and inefficient to support the arc part in vertical wall semicircle arch roadway, which will be illustrated in Section 4 of this paper.

\section{Analysis of Bearing Capacities of U-Type Steel Support}

The analysis of bearing capacities of U-type steel support is complex because of the nonlinearity of the partial differential equations. From the aspect of boundary condition, the load imposed on the U-type steel support mainly comes from the coupling effect between the roadway surrounding rock and the support. The load imposed on the support is a combination of different types and its distribution is obviously nonlinear. From the aspect of constitutive relation, the plastic feature of steel cannot be neglected and must be dealt with properly. From the aspect of U-type steel structure, the section of $U$-type steel is sophisticated. Because of the difficulties of theoretical analysis, finite element method is the popular method in the present literature. In the following part, the bearing capacities of U-type steel support were analyzed using finite element method with ABAQUS.

\subsection{Models of Finite Element Analysis}

3.1.1. Geometric Parameters. The steel type of U-type steel support is $36 \mathrm{U}$. According to the national standard GB/T 4697-2008 [29], the geometric parameters of $36 \mathrm{U}$ are given in Figure 6. 


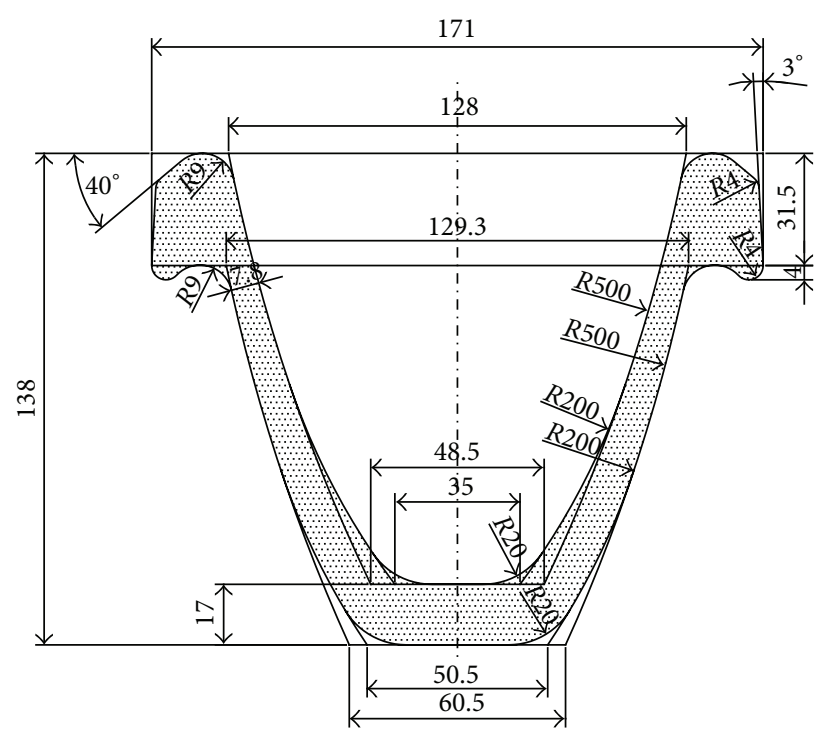

Figure 6: Geometric parameters of 36U.

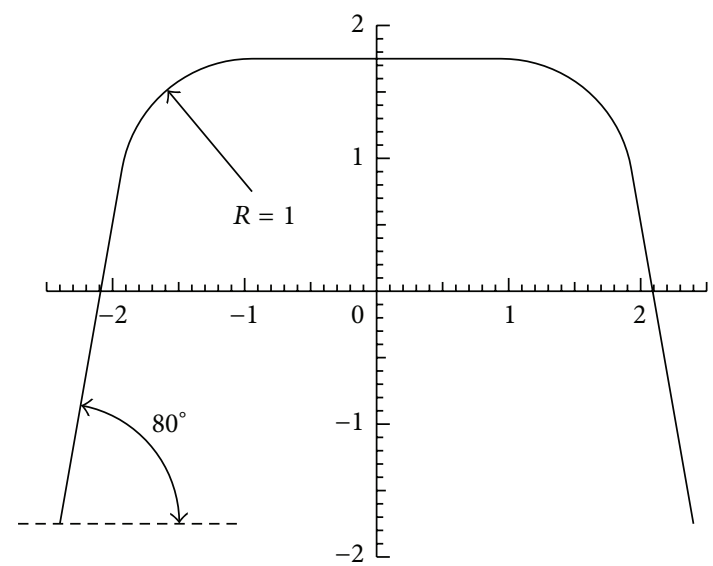

(a) Flat U-shaped support

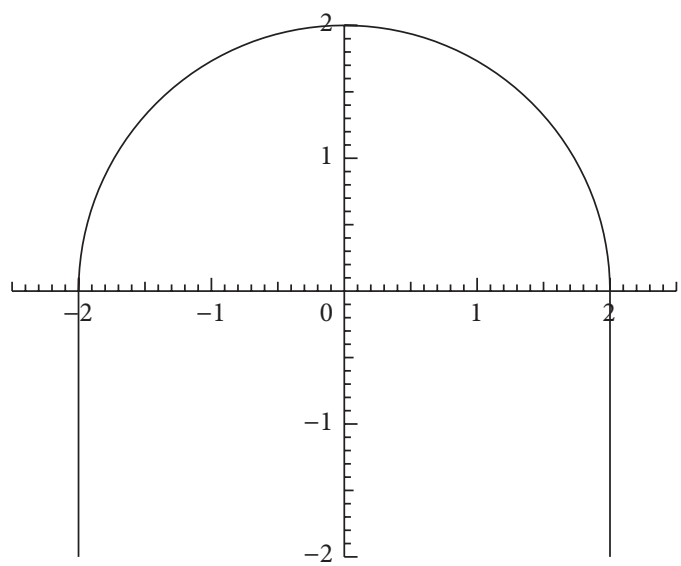

(b) Vertical wall semicircle arch section

FIgURE 7: Axial direction size of U-type steel support.

For convenience of expression, the U-type steel support of flat top U-shaped roadway is denoted by flat U-shaped support, and its structure and longitudinal size are shown in Figure 7(a); the U-type steel support of vertical wall semicircle arch roadway is denoted by vertical wall semicircle arch support, and its structure and longitudinal size are shown in Figure 7(b).

In order to simulate the interaction of U-type steel support and surrounding rock, the mechanics condition of the contact surfaces must be analyzed. The basic mechanics model of the interaction is the surface contact of two solid substances with different constitutive relations. Driven by the deformation of surrounding rock, that is, under the normal stress and friction on contact surfaces, the U-type steel support deformed. Taking vertical wall semicircle arch roadway as an example, the mechanics model is shown in Figure 8. In Figure 8, the dash area is surrounding rock, the dot area is roadway, and the arched thick black line between dash area and dot area is U-type steel support.

3.1.2. Material Parameters. The mechanics parameters of surrounding rock are specified in Section 2. The friction coefficient between coal and steel is 0.2 [30].

According to national standard GB/T 4697-2008 [29], the material specification of $36 \mathrm{U}$ is $20 \mathrm{MnK}$ steel. According to the tensile testing result of $20 \mathrm{MnK}$ steel, the yield strength is $350 \mathrm{MPa}$, the tensile strength is $530 \mathrm{MPa}$, and elongation at rupture is $20 \%$. The mechanics parameters of $20 \mathrm{MnK}$ are given in Table 1 [30].

The typical constitutive relation of low carbon steel is shown in Figure 9(a) [31]. In order to reduce the computational difficulty of finite element method, simplification of the constitutive relation is employed, as shown in Figure 7(b). 


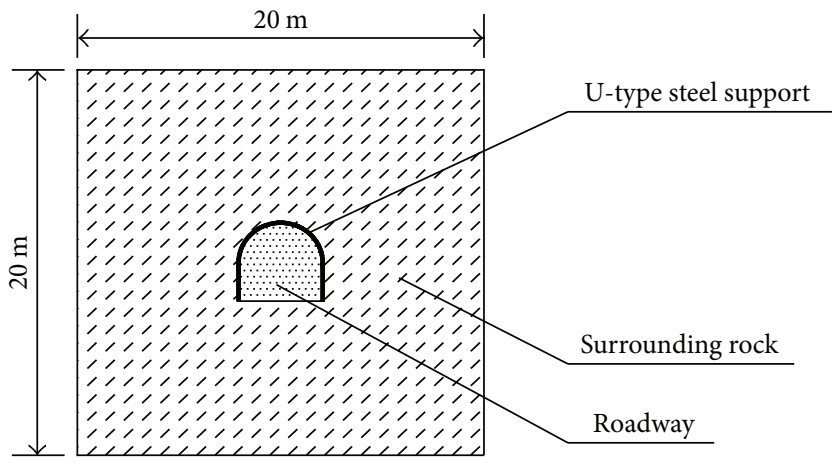

FIGURE 8: Mechanics model of the interaction of U-type steel support and surrounding rock.

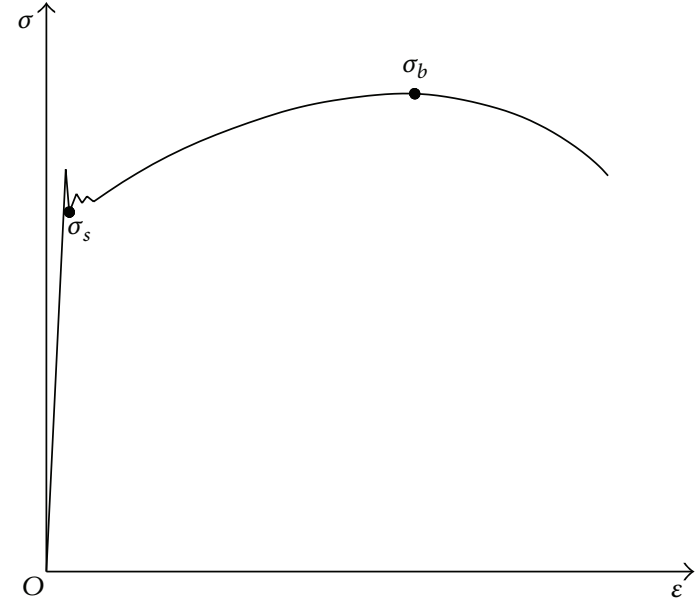

(a) Experimental constitutive relation

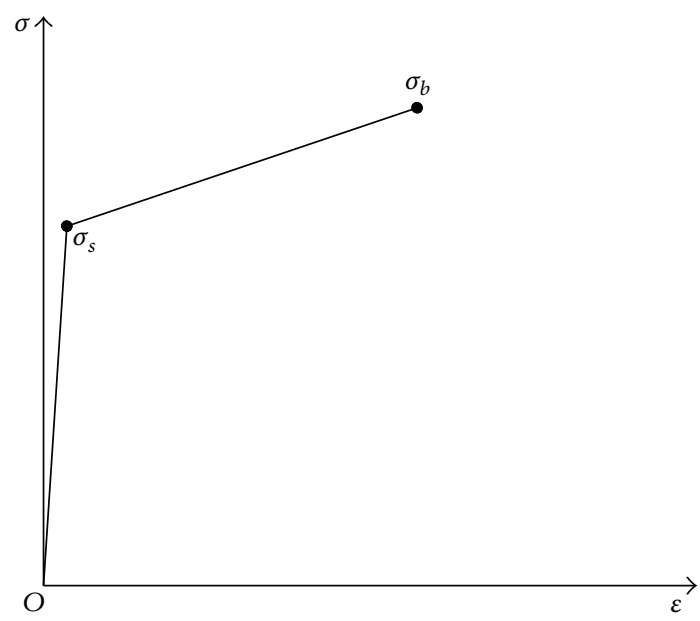

(b) Simplified constitutive relation

FIGURE 9: Constitutive relation of low carbon steel.

TABLE 1: Mechanics parameters of $20 \mathrm{MnK}$.

\begin{tabular}{lccc}
\hline Elastic modulus & Shear modulus & Poisson ratio & Density \\
\hline $200 \mathrm{GPa}$ & $79 \mathrm{GPa}$ & 0.26 & $7850 \mathrm{~kg} / \mathrm{m}^{3}$ \\
\hline
\end{tabular}

The curve in Figure 7(a) is replaced with lines, which is piecewise linear. According to the yield strength, tensile strength, elongation at rupture, and elastic modulus, the coordinates of point $\sigma_{s}$ and point $\sigma_{b}$ in Figure $9(\mathrm{~b})$ are $(0.00175,350)$ and $(0.20265,530)$, respectively.

3.2. Results of the Finite Element Analysis. The results of stress were obtained, as shown in Figure 10. The maximum of von Mises stress of flat top U-shape support is slightly larger than that of vertical wall semicircle arch support with a ratio of 1.057 to 1 . Although the von Mises stress of the upper rim of flat top U-shape support is above $300 \mathrm{MPa}$ while most of the part of the upper rim of flat top U-shape support in vertical wall semicircle arch support lies between $150 \mathrm{MPa}$ and $250 \mathrm{MPa}$, the flat top U-shape support deformed elastically under the von Mises yield criterion.
The results of displacement are shown in Figure 11. The maximum of displacement of flat top U-shape support is three times bigger than that of vertical wall semicircle arch support, but they are at the same scale. The main distinction between flat top U-shape support and vertical wall semicircle arch support is beam and arch. The bearing capacity of arch is better than beam. Considering the analysis of stress and displacement, the conclusion that, from a mechanics perspective, U-type steel support can fulfill the requirement of surrounding rock supporting in flat top U-shape roadway and vertical wall semicircle arch roadway can be made.

\section{Field Measurements}

In order to prove the correctness of the theoretical analysis and the justifiability of the finite element analysis, an industrial experiment was conducted in the return airway of working face 3204, which belonged to Zouzhuang coal mine of Anhui Shenyuan Coal Chemical Co. Ltd. Working face 3204 was arranged in No. 32 coal seam, which was a typical three-soft coal seam (the three-soft coal seam in the paper particularly means soft coal seam with soft roof and soft floor). The geological conditions of the coal seam are as 


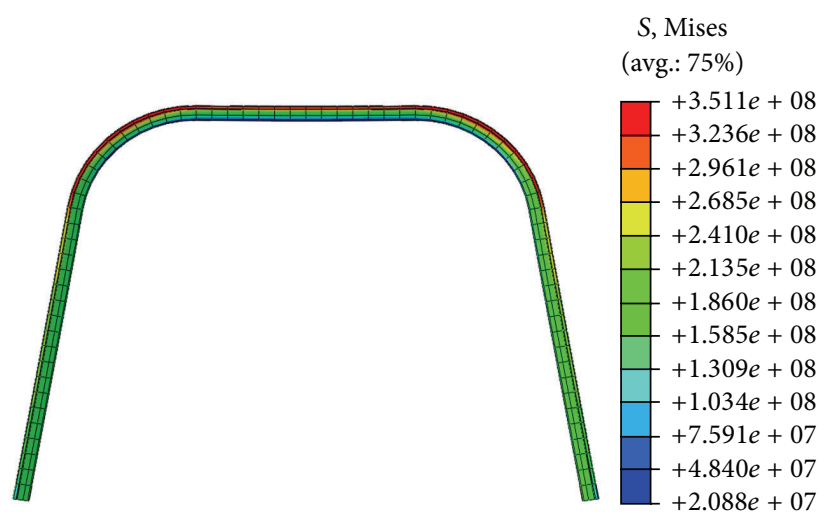

(a) Flat U-shaped support

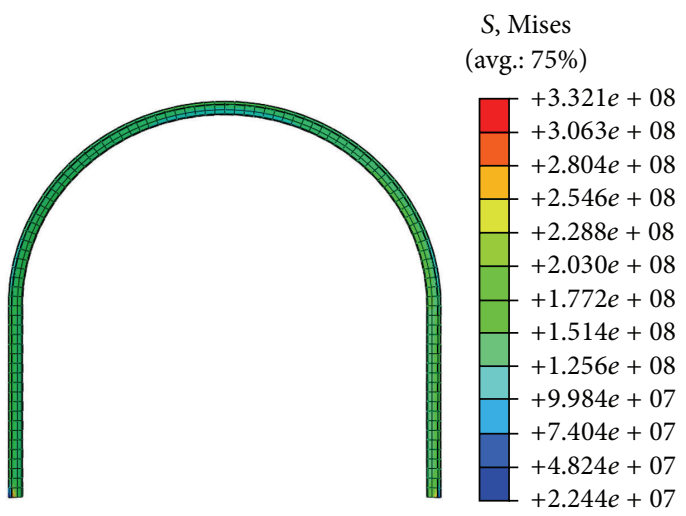

(b) Vertical wall semicircle arch support

FIGURE 10: The simulation stress results of the two supports.

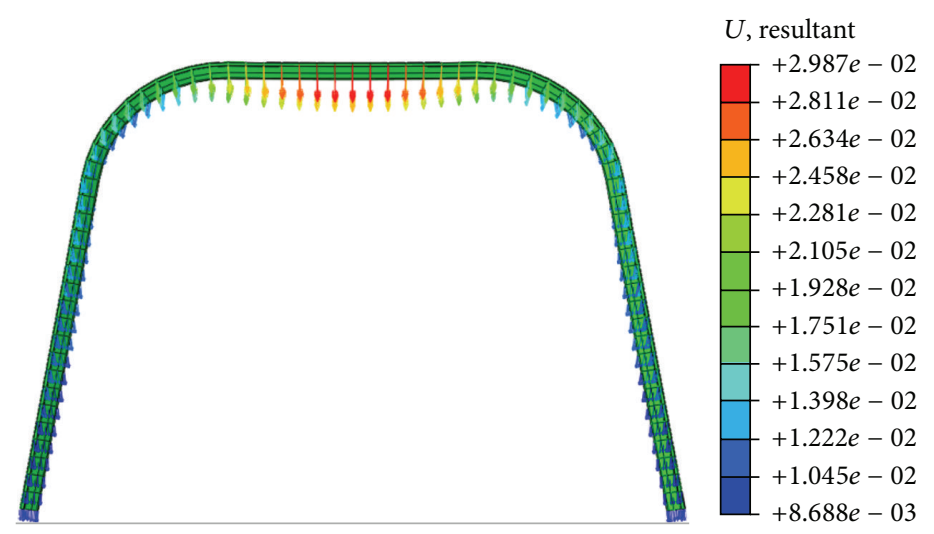

(a) Flat U-shaped support

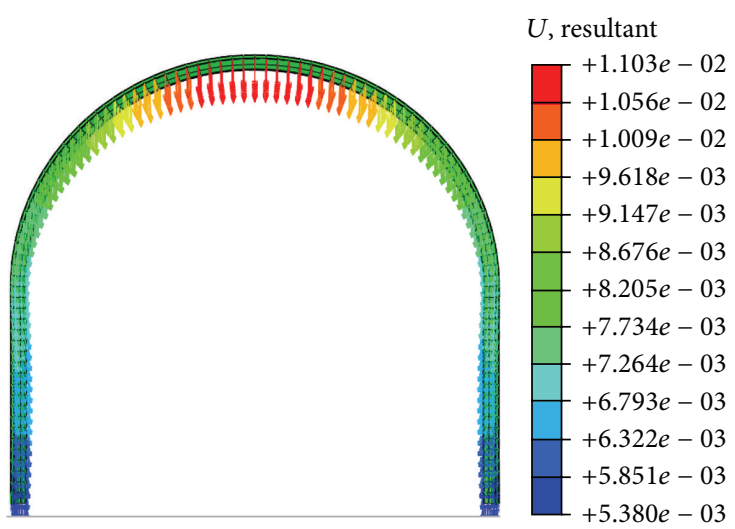

(b) Vertical wall semicircle arch support

FIgURE 11: The simulation displacement results of the two supports.

follows: the depth is $720 \mathrm{~m}$, the average thickness is $3 \mathrm{~m}$, and the Protodyakonov scale of hardness is 0.3 . The lithology of immediate roof is mudstone, with an average thickness of $7.2 \mathrm{~m}$, and the Protodyakonov scale of hardness is 1.3. The lithology of the immediate floor is mudstone, with an average thickness of $3.3 \mathrm{~m}$, and the Protodyakonov scale of hardness is 1.1. It is noted that the high gas content of the coal seam also has an impact on the excavation of the return airway. Regarding this, the comprehensive gas flow characteristics and the hard-to-drain problem of the coal seam are also investigated [32-34], and the gas problem will not be detailed in this paper.

In the excavation of the return airway, the roadway section of the first half is flat U-shaped section. As a comparison, the arched-top trapezoid was chosen as the roadway section of the remaining part, as shown in Figure 12. It should be noticed that the roadway section was arched-top trapezoid in the first or the initial mining process of working face 3204. Based on the geometric characteristic of arched-top trapezoid and the equipment condition in Zouzhuang coal mine, the "U-type steel support + advanced hydraulic support (model ZQL $2 \times 4000 / 18 / 35)$ + timber crib" was chosen as advanced support technique, as shown in Figure 12(a).
At the second mining process, the section of the return airway was flat U-shaped section and the respective advanced support technique was "U-type steel support + advanced hydraulic support (model ZQL $2 \times 4000 / 18 / 35)$ ), as shown in Figure 12(b).

4.1. Measurement of Roadway Deformation. Two observation points were established in the return airway, as shown in Figure 13. Observation point $\mathrm{A}$ was set in the second half of the return airway, that is, the arched-top trapezoid roadway, with $130 \mathrm{~m}$ ahead of open-off cut, as shown in Figure 13(c). Observation point B was set in the first half of the return airway, that is, the flat U-shaped roadway, with $130 \mathrm{~m}$ ahead of the median line, as shown in Figure 13(b). The accuracy of measurement was required to be $1 \mathrm{~mm}$ and cross measurement method was adopted. The deformation of the second-half return airway was recorded with the method described as follows: the first value of deformation was zero; when the advance of working face increased to 5 meters, the second recording was taken; when the advance of working face increased to 10 meters, the third recording was taken and the rest can be done in the same manner. When 


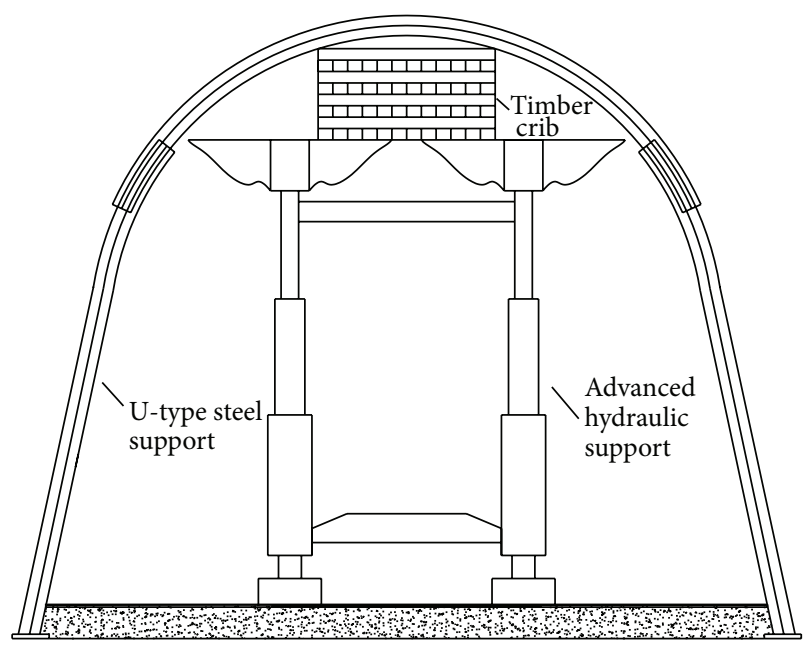

(a) Arched-top trapezoid roadway

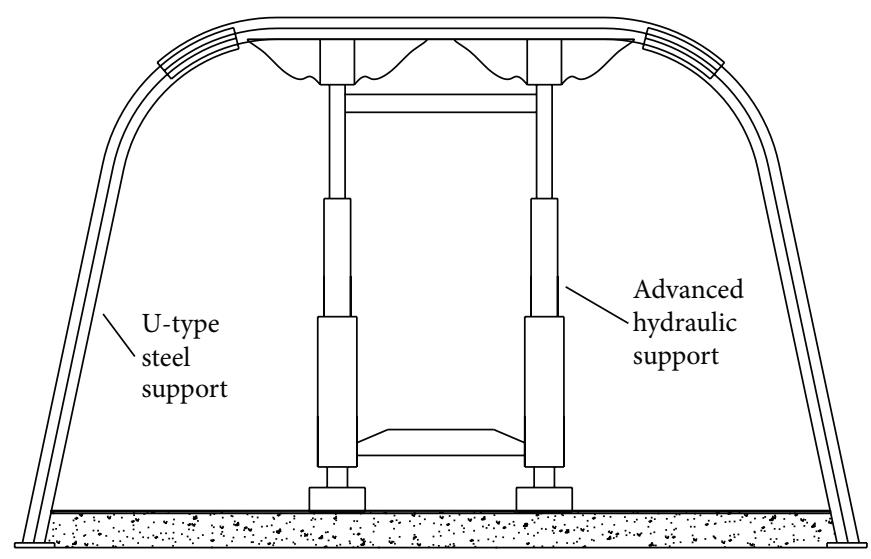

(b) Flat top U-shape roadway

Figure 12: Scheme of two different advanced support techniques.

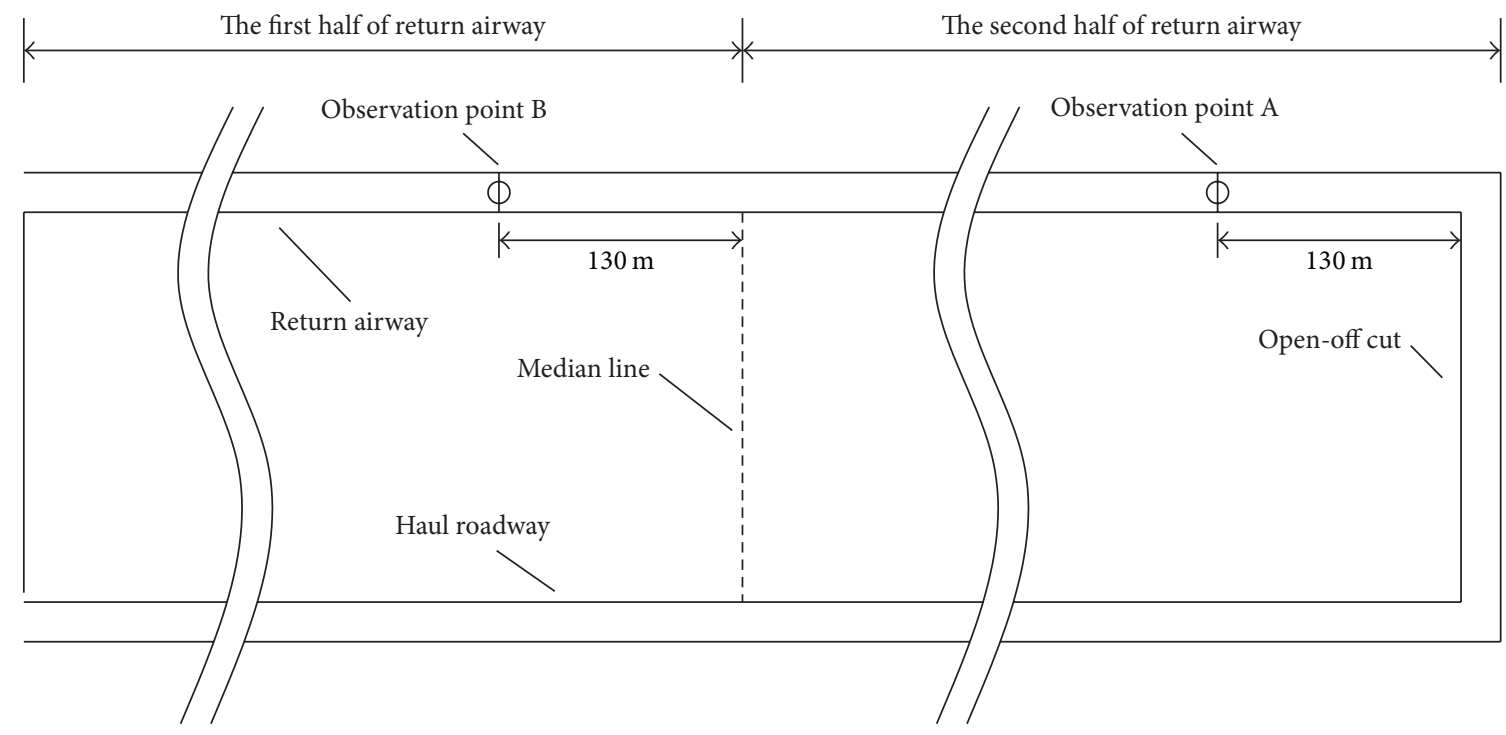

(a) Establishment of observation points in working face 3204

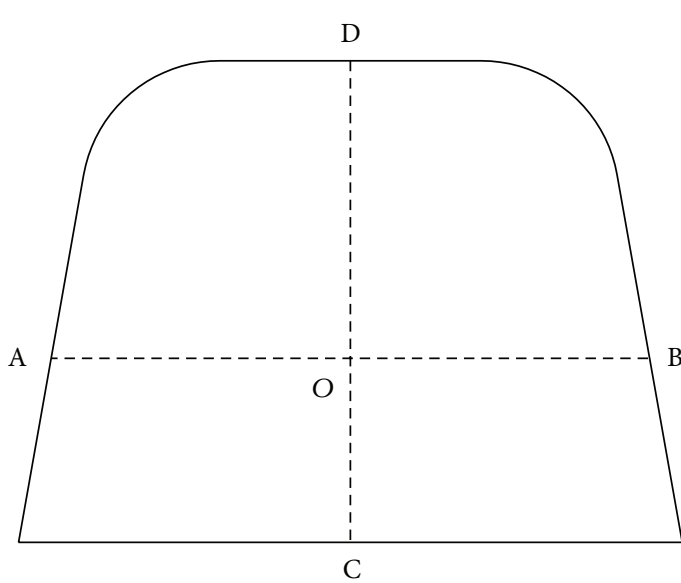

(b) Diagram of observation point $\mathrm{B}$

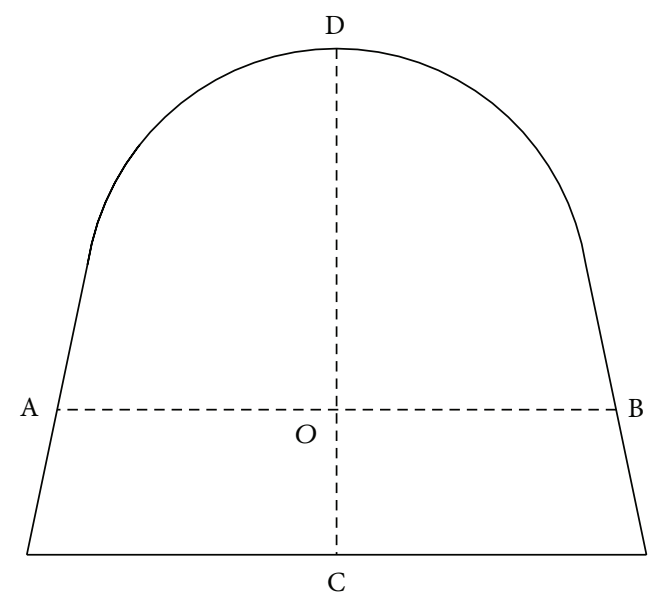

(c) Diagram of observation point A

FIGURE 13: Deformation measurement of roadway surrounding rock. 


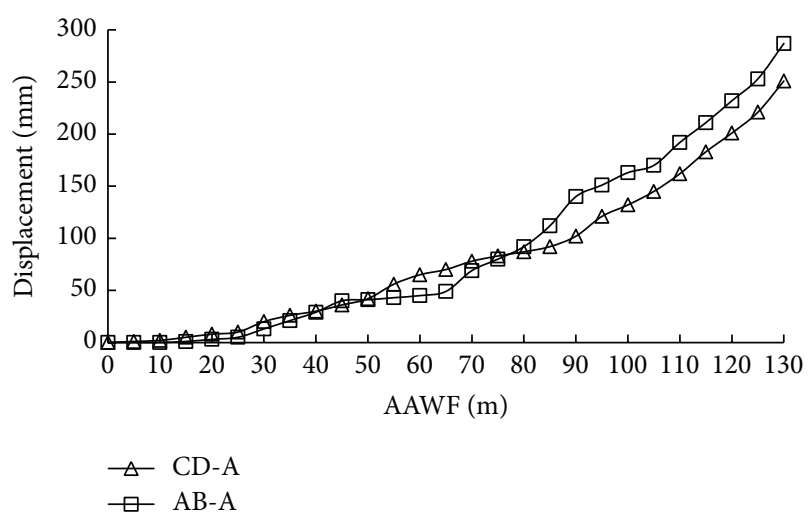

(a) Observation point $\mathrm{A}$

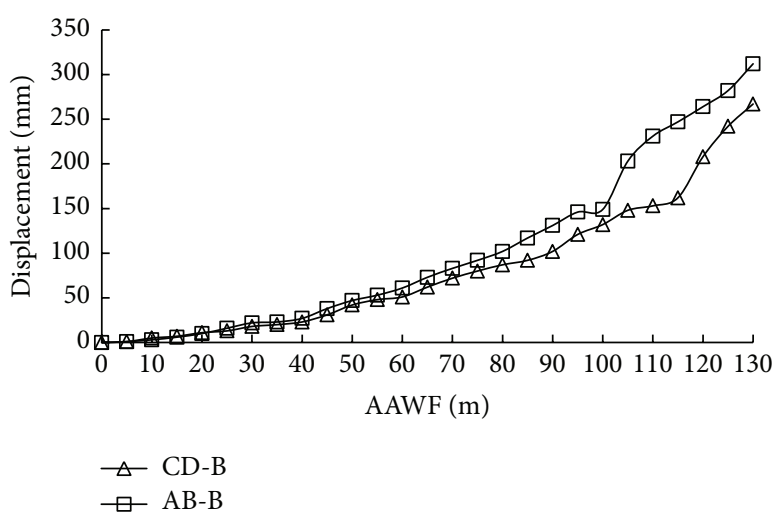

(b) Observation point $\mathrm{B}$

FIGURE 14: Deformation of roadway surrounding rock.

the working face reached the median line, the record of the first-half return airway deformation was started with the method described as follows: the first value of deformation was zero; when the advance of working face increased to 5 meters, the second recording was taken; when the advance of working face increased to 10 meters, the third recording was taken and the rest can be done in the same manner.

According to the measurement statistics of the roadway surrounding rock deformation, the deformation curves are generated, as shown in Figure 14. In Figure 14, the change of distance between points $\mathrm{A}$ and $\mathrm{B}$ at observation point $\mathrm{A}$ is denoted by $\mathrm{AB}-\mathrm{A}$, and the rest can be done in the same manner, that is, CD-A, AB-B, and CD-B. The abscissa axis was the accumulation of the advance of working face, denoted by AAWF.

According to Figure 14, the maximum between AB-B and CD-B is $312 \mathrm{~mm}$, which is slightly bigger than the maximum between $\mathrm{AB}-\mathrm{B}$ and $\mathrm{CD}-\mathrm{B}$. During the whole mining process of working face 3204, the surrounding rock of return airway kept stable. Field measurement showed that the support technique was proper and the stability of roadway surrounding rock was successfully controlled during the mining process. The conclusion that the flat top U-shape roadway can fulfill the stabilization requirement of surrounding rock during mining was proved by field measurements.

4.2. Measurement of Working Face Efficiency. During the mining of working face 3204, working time cycle of shearer was recorded, which consisted of waiting time, working time, and shutdown time. When the working face was around observation point $\mathrm{A}$, we took 13 records of the working time cycle of shearer. When the working face was around observation point $\mathrm{B}$, another 9 records of the working time cycle of shearer were taken. The distributions of working time cycle of shearer in the arched-top trapezoid roadway and flat top U-shape roadway were shown, respectively, in Figure 15.

According to Figure 15, the main difference of cycle time between arched-top trapezoid roadway and flat top U-shape roadway was that the waiting time at the end of the working face in arched-top trapezoid roadway was much longer than

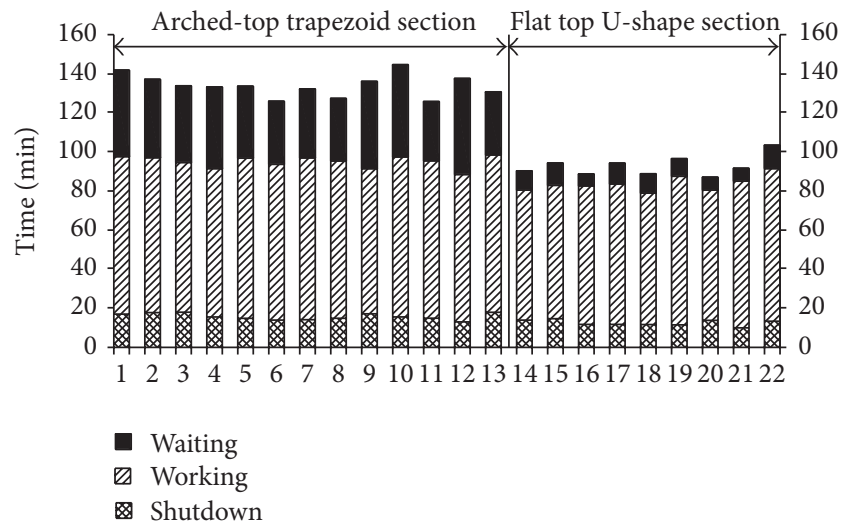

FIGURE 15: Loop time distribution of shearer.

that of flat top U-shape roadway, which was caused by the procedure of retrieving timber crib on the advanced hydraulic support. The procedure of retrieving timber crib on the advanced hydraulic support is rather too sophisticated and dangerous, which has increased the labor intensity of workers, reduced the efficiency of the working face, and restricted the safe mining. But the application of flat top Ushape roadwayovercame the hazards of arched-top trapezoid roadway, increased the efficiency of the working face, and reduced the labor intensity of workers with the guarantee of roadway surrounding rock stability. Thus, the flat top Ushape roadway should be preferred in similar geological and equipment conditions.

\section{Conclusions}

(1) After reviewing the former papers involving the analytic method of solving the stress and displacement of roadway surrounding rock, the roadway surrounding rock mechanics model was established, and the complex function method was adopted to obtain the surrounding rock displacement functions and stress functions of flat top U-shape roadway and vertical 
wall semicircle arch roadway. The results showed that the surrounding rock displacement distribution laws of the roadway edge are similar and the area of plasticity proportion in flat top U-shape roadway surrounding rock resembles that in vertical wall semicircle arch roadway with a ratio of 1.10 to 1 .

(2) After reviewing the former papers concerning the mechanics property of U-type steel support, the finite element model was established to analyze the mechanics property of flat U-shaped support and vertical wall semicircle arch support under the interaction with roadway surrounding rock, respectively. The results showed that, from a mechanics perspective, U-type steel support can fulfill the requirement of surrounding rock supporting in flat top U-shape roadway and vertical wall semicircle arch roadway.

(3) An industrial experiment was conducted to inspect the correctness of the theoretical analysis. During the whole mining process of working face 3204, the surrounding rock of return airway kept stable. Field measurement of surrounding rock displacement showed that the support technique was proper and the stability of roadway surrounding rock was successfully controlled during the mining process. The conclusion that the flat top U-shape roadway can fulfill the stabilization requirement of surrounding rock during mining was proved by field measurements. Field measurement of working face efficiency showed that the application of flat top U-shape roadway overcame the hazards of arched-top trapezoid roadway, increased the efficiency of the working face, and reduced the labor intensity of workers with the guarantee of roadway surrounding rock stability. Thus, the flat top U-shape roadway should be preferred in similar geological and equipment conditions.

\section{Competing Interests}

The authors declare that they have no competing interests.

\section{Acknowledgments}

Financial support for this work was provided by the National Natural Science Foundation of China (no. 51374200), the Natural Science Foundation of Jiangsu Province (no. BK20140208), the Graduate Students of Jiangsu Province Innovation Program (KYZZ16_0222), and the Priority Academic Program Development of Jiangsu Higher Education Institutions.

\section{References}

[1] B. Shen, "Coal mine roadway stability in soft rock: a case study," Rock Mechanics and Rock Engineering, vol. 47, no. 6, pp. 22252238, 2013.

[2] C. Zhang and S. Tu, "Control technology of direct passing karstic collapse pillar in longwall top-coal caving mining," Natural Hazards, vol. 84, no. 1, pp. 17-34, 2016.
[3] C. Sun, X. D. Zhang, and Y. J. Li, "Analysis of interaction between surrounding rock and support structure in high stressed soft rock roadway," Rock and Soil Mechanics, vol. 34, no. 9, pp. 2601-2607, 2013.

[4] J.-B. Bai, X.-Y. Wang, M.-K. Jia, and C.-J. Hou, "Theory and application of supporting in deep soft roadways," Chinese Journal of Geotechnical Engineering, vol. 30, no. 5, pp. 632-635, 2008.

[5] A. Z. Lv and L. Q. Zhang, Underground Tunnel Mechanics Analysis of Complex Function Method, Science Press, Beijing, China, 2007.

[6] N. I. Muskhelishvili, Some Basic Problems of the Mathematical Theory of Elasticity, Nauka, Moscow, Russia, 1966.

[7] K. J. Lu, Plane Elastic Complex Variable Method, Wuhan University Press, Wuhan, China, 2005.

[8] G. S. Bjorkman and R. Richards, "Harmonic holes-an inverse problem in elasticity," Journal of Applied Mechanics, vol. 43, no. 3, pp. 414-418, 1976.

[9] G. S. Bjorkman and R. Richards, "Harmonic holes for nonconstant fields," Journal of Applied Mechanics, vol. 46, no. 3, pp. 573$576,1979$.

[10] B. H. G. Brady and J. W. Bray, "The boundary element method for determining stresses and displacements around long openings in a triaxial stress field," International Journal of Rock Mechanics and Mining Sciences \& Geomechanics Abstracts, vol. 15, no. 1, pp. 21-28, 1978.

[11] N. D. Cristescu and I. Paraschiv, "The optimal shape of rectangular-like caverns," International Journal of Rock Mechanics and Mining Sciences \& Geomechanics Abstracts, vol. 32, no. 4, pp. 285-300, 1995.

[12] S. K. Dhir, "Optimization in a class of hole shapes in plate structures," Journal of Applied Mechanics, vol. 48, no. 4, pp. 905908, 1981.

[13] P. R. Dawson and D. E. Munson, "Numerical simulation of creep deformations around a room in a deep potash mine," International Journal of Rock Mechanics \& Mining Sciences and, vol. 20, no. 1, pp. 33-42, 1983.

[14] R. Kienzler and D. Zhuping, "On the distribution of hoop stresses around circular holes in elastic sheets," Journal of Applied Mechanics, vol. 54, no. 1, pp. 110-114, 1987.

[15] C. N. You, Calculation Theory of Metal Support in Tunnel, Coal Industry Press, Beijing, China, 2000.

[16] C. J. Hou, Tunnel Metal Support, Coal Industry Press, Beijing, China, 1989.

[17] Z.-L. Li, L.-M. Dou, W. Cai, G.-F. Wang, Y.-L. Ding, and Y. Kong, "Roadway stagger layout for effective control of gob-side rock bursts in the longwall mining of a thick coal seam," Rock Mechanics and Rock Engineering, vol. 49, no. 2, pp. 621-629, 2016.

[18] Y. H. Wang and R. Z. Zhou, "Metal support and its application in coal mine," Mine Construction Technology, no. 5, pp. 39-42, 1990.

[19] M. Z. Gao and H. M. Wang, "The selection of mental support types of caving mining roadway," Mine Pressure and Roof Management, no. 4, pp. 26-28, 2005.

[20] M. Z. Gao and W. Li, "Type optimized selection and application of closed metal supports," Coal Science and Technology, vol. 35, no. 2, pp. 16-19, 2007.

[21] W. Xie, S. Jing, T. Wang, Y. Ren, and N. Zhang, "Structural stability of U-steel support and its control technology," Chinese Journal of Rock Mechanics and Engineering, vol. 29, no. 2, pp. 3743-3748, 2010. 
[22] J. Z. Liu, Controlling mechanism of U-type steel frame buckling [Ph.D. thesis], China University of Mining and Technology, 2013.

[23] C. Wang, N. Zhang, C.-L. Han, G.-C. Li, and D.-Y. Qian, "Numerical analysis and application of the relationship between surrounding rock and U-shaped shed under leg locking," Journal of Mining \& Safety Engineering, vol. 28, no. 2, pp. 209213, 2011.

[24] X. G. Xue, Numerical optimization design of parameters of short distance top coal roadway support [Ph.D. thesis], Anhui University of Science \& Technology, 2012.

[25] Z. X. Dong and S. L. Wu, Tunnel Engineering, China University of Mining and Technology Press, Xuzhou, China, 2009.

[26] X. H. Ma and C. H. Zhao, "The application of circular arch section in three soft coal seams," Safety in Coal Mines, vol. 43, no. 12, pp. 204-206, 2012.

[27] Z. T. Wang, H. Q. Zhou, and Y. S. Xie, Mine Rock Mass Mechanics, China University of Mining and Technology Press, Xuzhou, China, 2007.

[28] G. C. Zhang and F. L. He, "Asymmetric failure and control measures of large cross-section entry roof with strong mining disturbance and fully-mechanized caving mining," Chinese Journal of Rock Mechanics and Engineering, vol. 35, no. 4, pp. 806-818, 2016.

[29] GB/T, "Hot-rolled U-type steel for mine timbering," GB/T 46972008, China Standard Press, Beijing, China, 2008.

[30] Y. F. Sun, Handbook of Steel, China Machine Press, Beijing, China, 2009.

[31] H. W. Liu, Mechanics of Materials, Higher Education Press, Beijing, China, 2004.

[32] L. Zhang, N. Aziz, T. Ren, J. Nemcik, and S. Tu, "Influence of coal particle size on coal adsorption and desorption characteristics," Archives of Mining Sciences, vol. 59, no. 3, pp. 807-820, 2014.

[33] L. Zhang, N. Aziz, T. Ren, J. Nemcik, and S. Tu, "Nitrogen injection to flush coal seam gas out of coal: an experimental study," Archives of Mining Sciences, vol. 60, no. 4, pp. 1013-1028, 2015.

[34] L. Zhang, C. Zhang, S. Tu, H. Tu, and C. Wang, "A study of directional permeability and gas injection to flush coal seam gas testing apparatus and method," Transport in Porous Media, vol. 111, no. 3, pp. 573-589, 2016. 


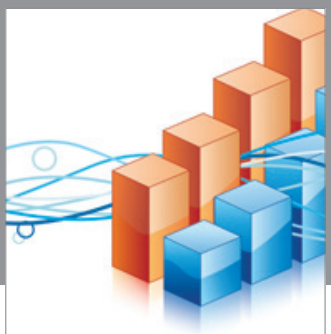

Advances in

Operations Research

vatem alat4

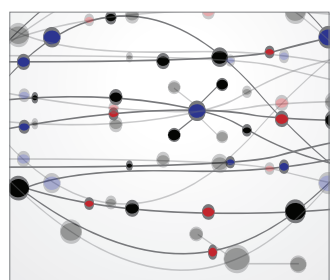

\section{The Scientific} World Journal
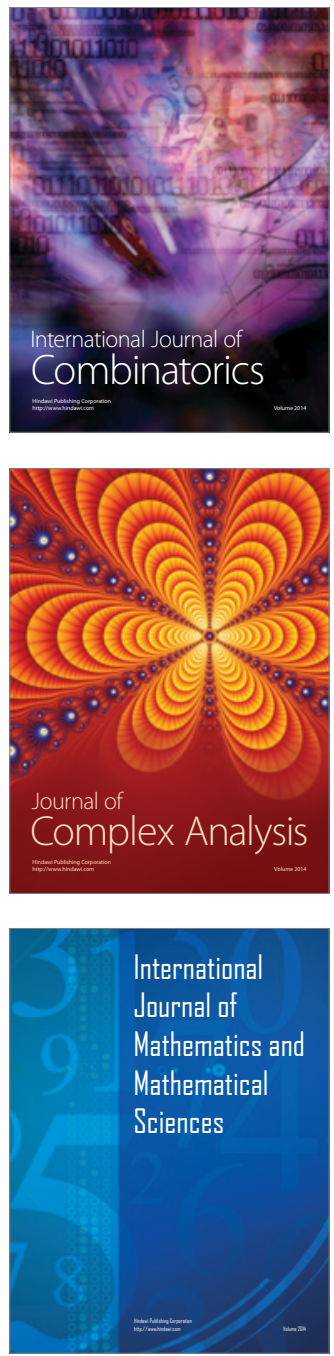
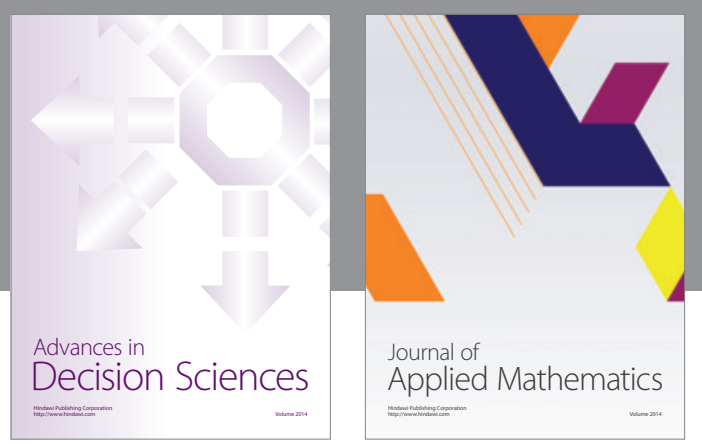

Algebra

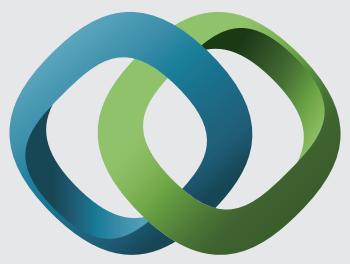

\section{Hindawi}

Submit your manuscripts at

http://www.hindawi.com
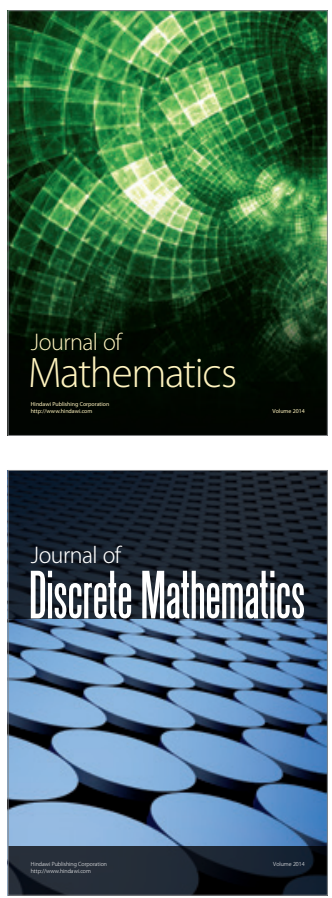

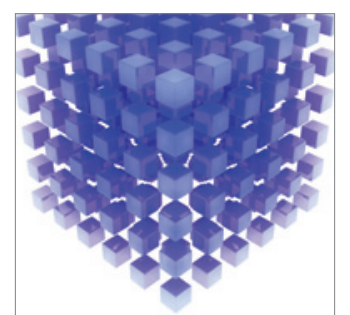

Mathematical Problems in Engineering
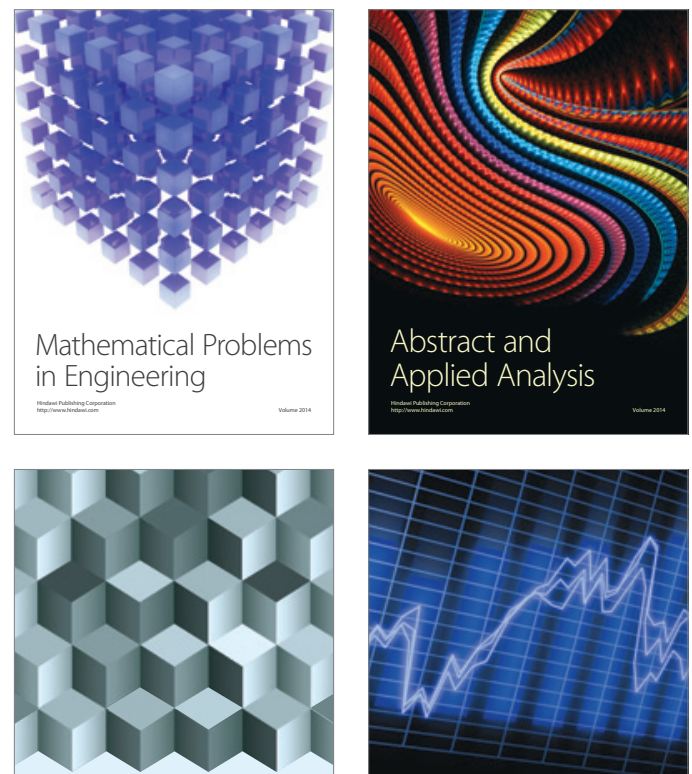

Journal of

Function Spaces

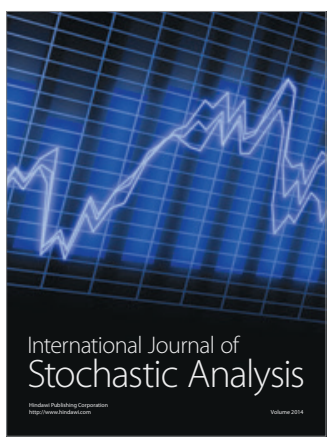

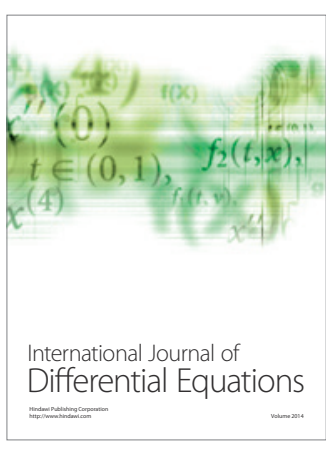
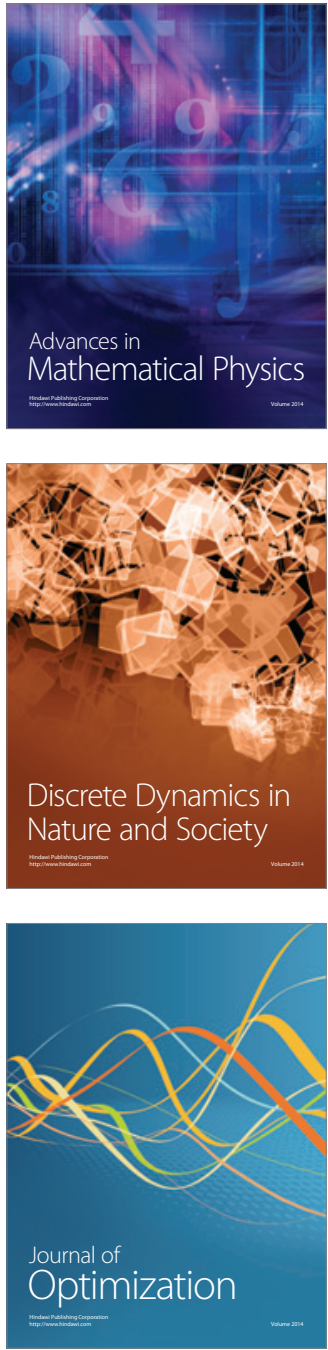